Article

\title{
Dysprosium Single-Molecule Magnets Involving 1,10-Phenantroline-5,6-dione Ligand
}

\author{
Olivier Galangau ${ }^{\circledR}$, Jessica Flores Gonzalez, Vincent Montigaud, Vincent Dorcet, \\ Boris le Guennic $\mathbb{D}^{\mathbb{D}}$, Olivier Cador and Fabrice Pointillart * (1) \\ Univ Rennes, CNRS, ISCR (Institut des Sciences Chimiques de Rennes) - UMR 6226, F-35000 Rennes, France; \\ olivier.galangau@univ-rennes1.fr (O.G.); jessica.flores-gonzales@univ-rennes1.fr (J.F.G.); \\ vincent.montigaud@univ-rennes1.fr (V.M.); vincent.dorcet@univ-rennes1.fr (V.D.); \\ boris.leguennic@univ-rennes1.fr (B.1.G.); olivier.cador@univ-rennes1.fr (O.C.) \\ * Correspondence: fabrice.pointillart@univ-rennes1.fr
}

Received: 3 April 2020; Accepted: 10 April 2020; Published: 15 April 2020

Abstract: The two mononuclear complexes of the formula [Dy $\left.(\mathrm{tta})_{3}(\mathbf{L})\right](\mathbf{1})$ and $\left[\mathrm{Dy}(\mathrm{hfac})_{3}(\mathbf{L})\right]$ (2) (where $\mathrm{tta}^{-}=2$-thenoytrifluoroacetylacetonate and $\mathrm{hfac}^{-}=1,1,1,5,5,5$-hexafluoroacetylacetonate) were obtained from the coordination reaction of the Dy $(\mathrm{tta})_{3} \cdot 2 \mathrm{H}_{2} \mathrm{O}$ or Dy $(\mathrm{hfac})_{3} \cdot 2 \mathrm{H}_{2} \mathrm{O}$ units with the 1,10-phenantroline-5,6-dione ligand ( $\mathbf{L})$. Their structures have been determined by $\mathrm{X}$-ray diffraction studies on single crystals, and they revealed a supramolecular assembly of tetramers through $\sigma-\pi$ interactions. Both complexes displayed a Single-Molecule Magnet (SMM) behavior without an external applied magnetic field. Magnetic relaxation happened through Orbach, Raman and Quantum Tunneling of the Magnetization (QTM). Wavefunction theory calculations were realized to rationalize the magnetic properties.

Keywords: dysprosium; 1,10-Phenantroline-5,6-dione; $\beta$-diketone; single molecule magnets; ab initio calculations

\section{Introduction}

The design of lanthanide coordination complexes is crucial for the development of emitting materials [1,2] and molecular magnetism fields [3-5]. On the one hand, the specific characteristic of the lanthanide ions, such as intense, long-lived and sharp-line emissions, makes them ideal candidates for a plethora of applications ranging from luminescent- and bio-sensors [6,7], Organic Light-Emitting Diodes (OLEDs) [8], time-resolved fluoro-immunoassays [9] and imaging [10,11]. Nevertheless, the observation of such emissions needs to be sensitized by an indirect process, since the forbidden Laporte $f-f$ transitions [12] have very weak absorption coefficients which lead to an inefficient direct excitation process. The indirect sensitization process is achieved using organic chromophores which possess adequate triplet and/or intra-ligand charge transfer excited states to efficiently perform an energy transfer to the spectroscopic levels of the lanthanide $[13,14]$. On the other hand, the strong magnetic anisotropy associated with a high magnetic moment makes lanthanide ions suitable for the observation of Single-Molecule Magnet (SMM) behavior [15]. Such magnetic bistability could find interest in potential applications such as high density storage devices [16], quantum computing [17] or spintronics [18]. In order to observe SMM behavior, the crucial parameter is the magnetic anisotropy, which must be uniaxial or planar depending on the electronic distribution of the $f$ electrons, i.e., oblate or prolate [19]. The control of the magnetic anisotropy is driven by the nature and the position of the ligands around the metal center. Thus, recently, the use of cyclopentadienyl-based ligands has allowed for the design of mononuclear lanthanide SMMs with a high blocking temperature [20-23]. These two research fields highlight the important role of the organic ligands associated to the lanthanide ion. 
To go one step forward, more complex ligands with multi-functionality, such as the combination of redox-activity with multi coordination sites, could be used. These kind of ligands can allow the observation of multi-emission or -SMM behavior [24-27]. In this context, the 1,10-phenantroline-5,6-dione (L) appears as a promising multifunctional ligand since it combines two potential coordination sites with electro-activity [28,29], leading to the design of potential multi-properties compounds, such as a combination of spin crossover and valence tautomerism, as has recently been proposed from a computational point of view [30]. Its electro-activity could be exploited to modulate the physical properties as a function of its oxidation state, i.e., to design redox magnetic and photo-emissive switches, as already published with other redox-active ligands [31-33]. The $\mathbf{L}$ ligand was employed to design both pure $4 f$ [34-39] and hetero-bimetallic $n d 4 f$ [40-42] coordination complexes to study their biological activities and photo-physical properties. It is worth noting that the elaboration of hetero-bimetallic compounds implies the reduction of the ligand in its 5,6-dihydroxy-1,10-phenantroline form. To the best of our knowledge, a magnetic study was not performed for lanthanide complexes involving the $\mathbf{L}$ ligand.

Thus, in the present article, we propose to analyze the magnetic properties of two mononuclear complexes of the formula $\left[\mathrm{Dy}(\mathrm{tta})_{3}(\mathbf{L})\right] \quad(\mathbf{1})$ and $\left[\mathrm{Dy}(\mathrm{hfac})_{3}(\mathbf{L})\right]$ (2) (where $\mathrm{tta}^{-}=2$-tenoytrifluoroacetylacetonate and $\mathrm{hfac}^{-}=1,1,1,5,5,5$-hexafluoroacetylacetonate) from both experimental and computational points of view.

\section{Results and Discussion}

\subsection{X-ray Structures}

$\left[\operatorname{Dy}(\operatorname{tta})_{3}(\mathbf{L})\right](\mathbf{1}) .1$ crystallized in the tetragonal space group I4 ( $\left.{ }^{\circ} 79\right)$ (Table S1). The asymmetric unit is composed of one complex of $\left[\mathrm{Dy}(\mathrm{tta})_{3}(\mathbf{L})\right]$, and its Ortep view is depicted in Figure S1. The Dy(tta) $)_{3}$ unit is linked to the 1,10-phenantroline-5,6-dione ligand (L) through the nitrogen bidentate coordination site and to three tta- ancillary ligands (Figure 1a). The nature and the arrangement of these ligands led to a N2O6 environment with a slightly distorted triangular dodecahedron symmetry (TDD-8) (the distortion from the ideal symmetry $\mathrm{CShM}_{\mathrm{TDD}-8}=0.455$ was determined using the SHAPE 2.1 program [43] with CShM = Continuous Shape Measures).
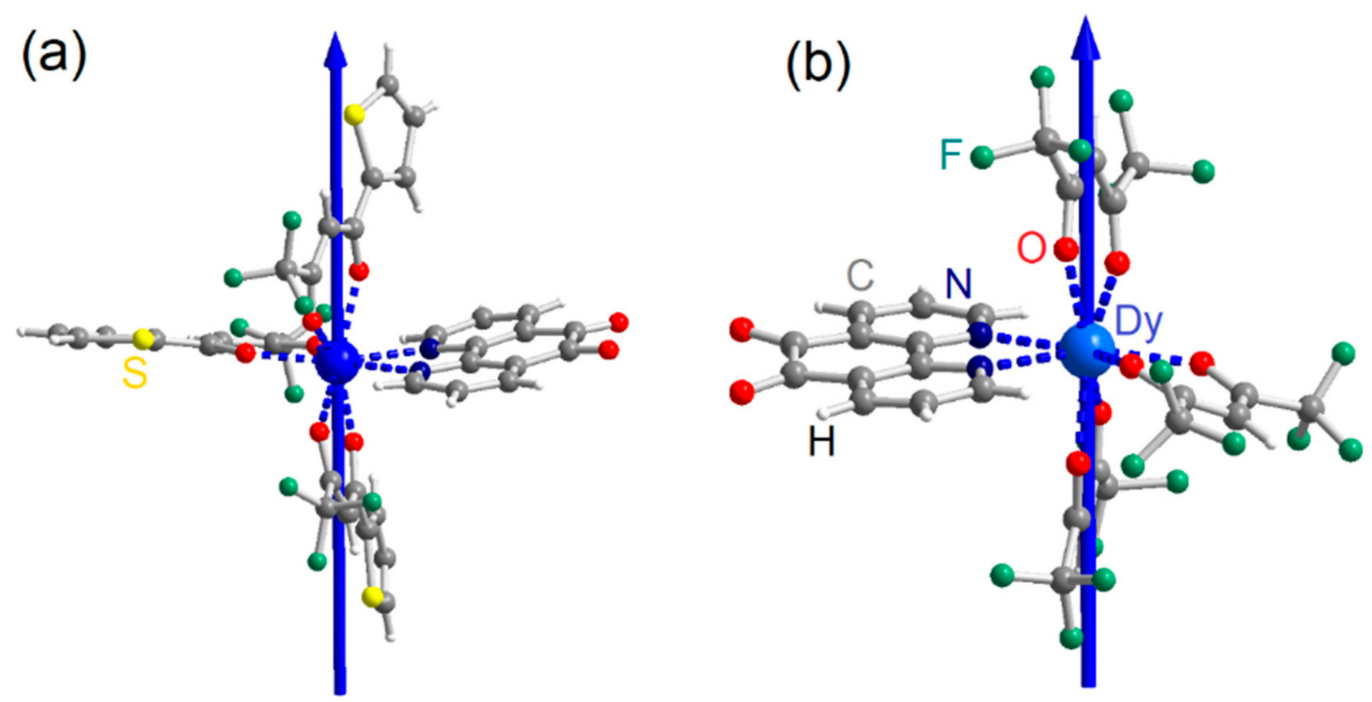

Figure 1. Molecular structures of $\mathbf{1}(\mathbf{a})$ and $\mathbf{2}(\mathbf{b})$ with representation of the main component $\left(\mathrm{g}_{\mathrm{z}}\right)$ of the computed ground state anisotropy axis. Color code: gray: carbon, dark blue: nitrogen, red: oxygen, green: fluoride, yellow: sulfur, blue: dysprosium, white: hydrogen. 
The average Dy- $\mathrm{O}_{\text {tta }}$ and Dy-N distances are 2.321(8) $\AA$ and 2.572(10) $\AA$, respectively. The 1,10-phenantroline-5,6-dione oxidation state of the ligand was confirmed by the carbonyl bond lengths of 1.194(16) and 1.228(17) A.

The crystal packing revealed a supramolecular assembly leading to the formation of tetramers through $\pi-\sigma$ interactions between one carbonyl group and the central aromatic ring of the phenantroline moiety (O1 $\cdots \mathrm{C}_{\pi}$ distances range from 2.885 to $3.168 \AA$ ) (Figure 2a). $\pi-\pi$ interactions between the thiophene ring of the tta ligand and the same central aromatic ring of the phenantroline moiety participate to the stabilization of the tetramers. The shortest Dy-Dy intermolecular distance is $9.845 \AA$.
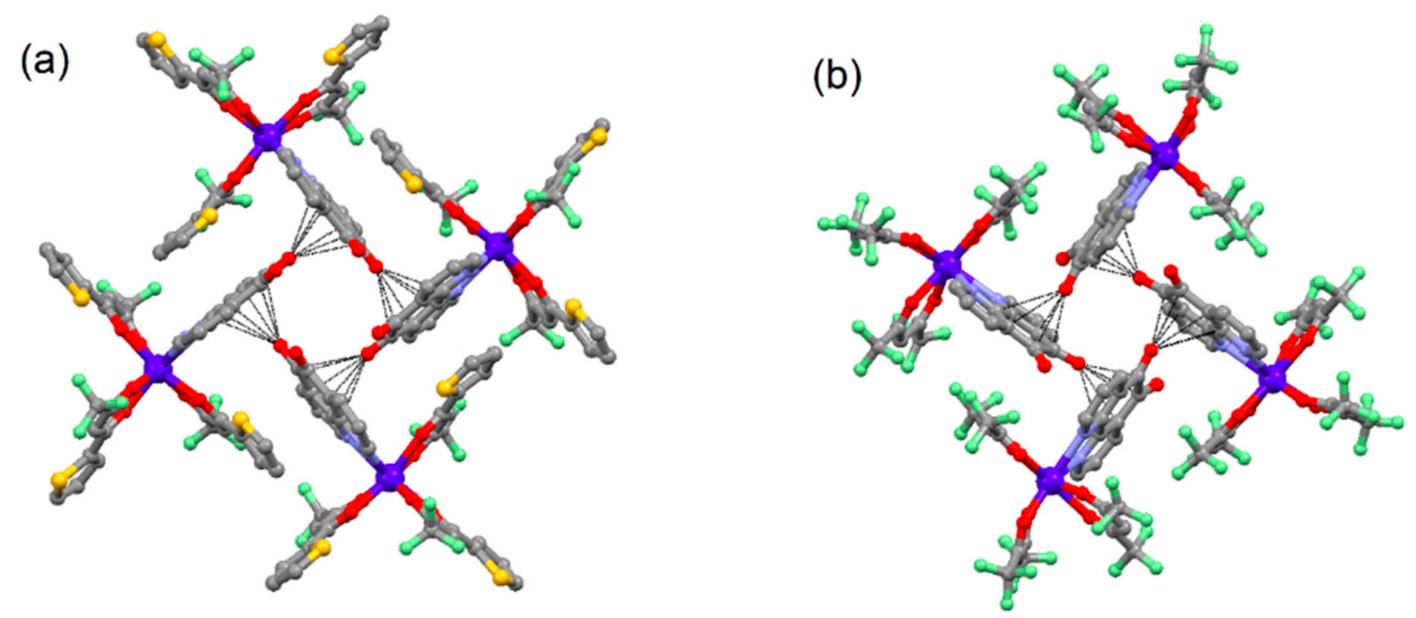

Figure 2. Crystal packing of (a) 1 and (b) 2 with highlights of the $\pi-\sigma$ interaction.

$\left[\mathrm{Dy}(\mathrm{hfac})_{3}(\mathbf{L})\right](\mathbf{2})$. The X-ray structure of $\mathbf{2}$ is similar to that of $\mathbf{1}$. It crystallized in the tetragonal I4 space group ( $\mathrm{N}^{\circ} 82$ ) (Figure S2 and Table S1). The Dy ${ }^{\mathrm{III}}$ ion is coordinated to three hfac' ligands and to $\mathbf{L}$ through the nitrogen bischelating coordination site (Figure $1 \mathrm{~b}$ ). The difference of the electron withdrawing between $\mathrm{tta}^{-}$and hfac ${ }^{-}$led to a slight variation of the Dy- $\mathrm{O}_{\mathrm{hfac}}$ and Dy-N bond lengths with 2.333(8) and 2.535(8) $\AA$, respectively. The N2O6 coordination sphere with a $\mathrm{D}_{2 \mathrm{~d}}$ triangular dodecahedron symmetry is slightly more distorted than the one determined for $\mathbf{1}\left(\mathrm{CShM}_{\mathrm{TDD}-8}=\right.$ 0.726). The oxidation of the $L$ ligand is retained with $C=O$ bond lengths of 1.210(14) and 1.198(12) $\AA$. The supramolecular tetramers are stabilized only by the $\pi-\sigma$ interaction $\left(\mathrm{O} 1 \cdots \mathrm{C}_{\pi}\right.$ distances range from 2.802 to $3.148 \AA$ ) (Figure $2 b$ ), since the thiophene rings were replaced by CF3 groups. The shortest Dy-Dy intermolecular distance is $9.247 \AA$.

The two complexes 1 and 2 highlighted crystal packing which completes the different intermolecular arrangements that could be observed in the literature for compounds made from tris( $\beta$-diketonate) of lanthanide associated with phenanthroline derivatives. Indeed, non-substituted phenantroline or $\pi$-extended phenantroline led to parallel complex arrangements thanks to $\pi-\pi$ interactions [44], phenantroline substituted with an electron donor group such as tetrathiafulvalene led to "head-to-tail" parallel dimers of complexes through donor-acceptor and $\pi-\pi$ interaction [45], and phenantroline substituted by an electron rich atom with lone pairs led to perpendicular arrangements of complexes like for compounds $\mathbf{1}$ and $\mathbf{2}$.

\subsection{Magnetic Properties}

\subsubsection{Ab Initio Calculations}

State-Averaged-Complete Active Space Self-Consistent Field/Restricted Active Space State Interaction including Spin Orbit coupling (SA-CASSCF/RASSI-SO) calculations were performed for the two mononuclear complexes to extend the understanding and to rationalize the magnetic properties (see computational details). The computed energy splittings are depicted in Tables S2 and S3. For both systems, the Dy ${ }^{\mathrm{III}}$ center presents an almost pure Ising ground state, $92 \% \mathrm{M}_{\mathrm{J}}=\mid \pm 15 / 2>$ 
for 1 and $95 \% M_{J}=\mid \pm 15 / 2>$ for 2, defined by a g-tensor with a main component $g_{Z}=19.43$ for 1 and $g_{Z}=19.56$ for 2 and exhibiting negligible transversal components with $g_{X}=0.00, g_{Y}=0.01$ for 1 and $g_{X}=0.01, g_{Y}=0.01$ for 2. At this point, the Quantum Tunneling of the Magnetization (QTM) is expected weak, and a slow magnetic relaxation of the magnetization at zero field should be observable. One could observe that the weak difference of the uniaxial character of the magnetic anisotropy ground state follows the distortion trend of the coordination sphere. The main component of the ground state g-tensor of the Dy ${ }^{\mathrm{III}}$ center for each complex is represented in Figure 1 . To give more insights on the orientation of the magnetic axis, the molecular electrostatic potential is investigated using the home-made Calculated Molecular Multipolar Electrostatics (CAMMEL) software which uses previously calculated Local Properties (LOPROP) charges to compute the electrostatic potential on a sphere centered on the lanthanide ion (see computational details). The resulting potential for both molecules is represented in Figure S3 along with the orientation of the ground state anisotropy. For both systems, the main magnetic component appears perpendicular to the plane containing the 1,10-phenantroline-5,6-dione ligand, i.e., the most charged direction as expected for an oblate ion [19]. The matrix elements of the transition magnetic moments between the Stark sub-levels for the Kramers ion of each complex have been computed in order to give more insights into the relaxation mechanisms (Figure 3). At the molecular scale, no major difference between the two compounds was identified except the higher energy gap between the ground and first excited state for $\mathbf{1}(230.4 \mathrm{~K})$ than for 2 (194.3 K), as already observed when changing the hfac ${ }^{-}$ancillary ligands with $\mathrm{tta}^{-}$ones [45-47].
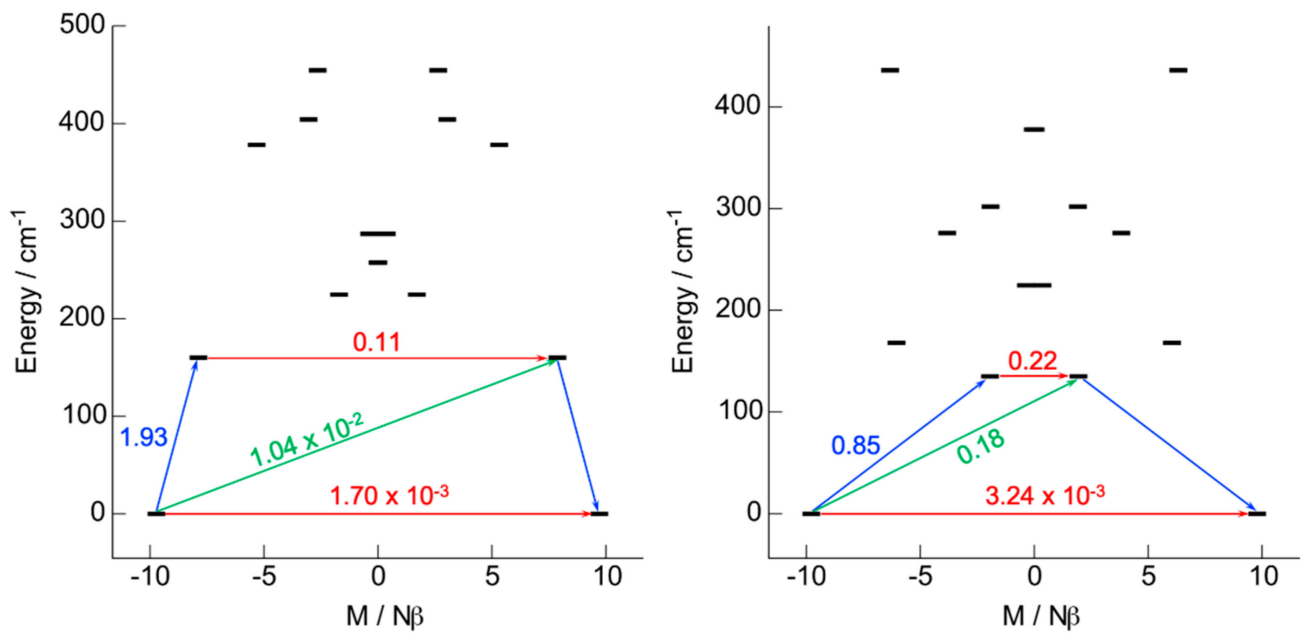

Figure 3. Energies (in $\mathrm{cm}^{-1}$ ) and $M$ (in $N \beta$ ) (where $N \beta=$ Bohr Magnetons) values for the Kramers doublet states of $\mathbf{1}$ (Left) and $\mathbf{2}$ (Right). The values of the magnetic (i.e., isotropic Zeeman) transition moments between the states are given for comparison. The horizontal red values correspond to QTM (for the GS) and Thermal Activated (TA)-QTM (for the ESs) mechanisms of the magnetization relaxation, whereas the blue and green arrows correspond to thermal and Orbach mechanisms, respectively.

\subsubsection{Static Magnetic Measurements}

The dc magnetic properties of $\mathbf{1}$ and $\mathbf{2}$ were determined by measuring their thermal dependence on the magnetic susceptibility (Figure 4). The room temperature values are $13.90 \mathrm{~cm}^{3} \cdot \mathrm{K} \cdot \mathrm{mol}^{-1}$ for compound 1 and $13.89 \mathrm{~cm}^{3} \cdot \mathrm{K} \cdot \mathrm{mol}^{-1}$ for compound 2 . These values are close to the expected one of $14.17 \mathrm{~cm}^{3} \cdot \mathrm{K} \cdot \mathrm{mol}^{-1}$ for an isolated Dy ${ }^{\mathrm{III}}$ ion $\left({ }^{6} \mathrm{H}_{15 / 2}\right.$ ground state multiplet) [48]. Decreasing the temperature, $\chi_{M} T$ decreases monotonically down to $11.19 \mathrm{~cm}^{3} \cdot \mathrm{K} \cdot \mathrm{mol}^{-1}$ for 1 and $11.45 \mathrm{~cm}^{3} \cdot \mathrm{K} \cdot \mathrm{mol}^{-1}$ for 2 due to the thermal depopulation of the $\mathrm{M}_{\mathrm{J}}$ states. Below $5 \mathrm{~K}$, the decreasing is more pronounced, probably due to dominant antiferromagnetic intermolecular interactions (Figure 4). 


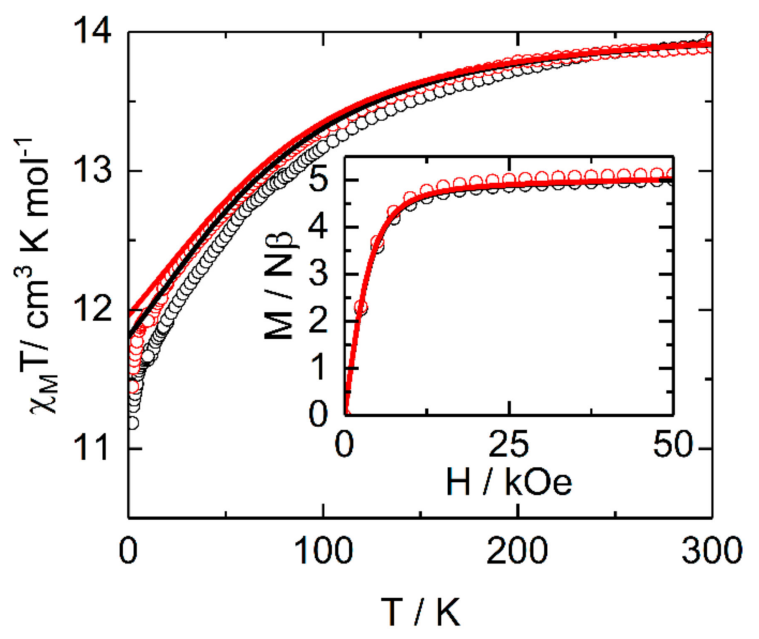

Figure 4. Temperature dependence of $\chi_{M} T$ for 1 (black open circles) and 2 (red open circles). In the inset, the field variations of the magnetization at $2 \mathrm{~K}$ for $\mathbf{1}$ (black open circles) and $\mathbf{2}$ (red open circles). Full black and red lines correspond to the best computed curves.

The magnetization at $2 \mathrm{~K}$ displayed classical behavior for the isolated highly anisotropic Dy ${ }^{\mathrm{III}}$ ion. The simulated curves reproduced the experimental $\chi_{M} T(\mathrm{~T})$ and $\mathrm{M}(\mathrm{H})$ measurements well, leading to the conclusions that the nature of the ground state and energy splitting are correctly computed and identified.

\subsubsection{Dynamic Magnetic Measurements}

The $\chi_{M}{ }^{\prime}$ (in-phase) and $\chi_{M}{ }^{\prime \prime}$ (out-of-phase) components of the ac susceptibility were measured for both compounds 1 and 2 . For both compounds, a $\chi_{M}{ }^{\prime \prime}$ was detected in the zero magnetic field, as suggested by ab initio calculations, with maxima localized at $310 \mathrm{~Hz}$ and $70 \mathrm{~Hz}$ at $2 \mathrm{~K}$, respectively for 1 and 2. They highlighted a frequency dependence of the in-phase (Figure S4) and out-of-phase signal of the magnetization (Figure 5), allowing an analysis of the temperature variations (Tables S4 and S5) of the magnetic susceptibility in the framework of an extended Debye model (see SI) $[49,50]$.

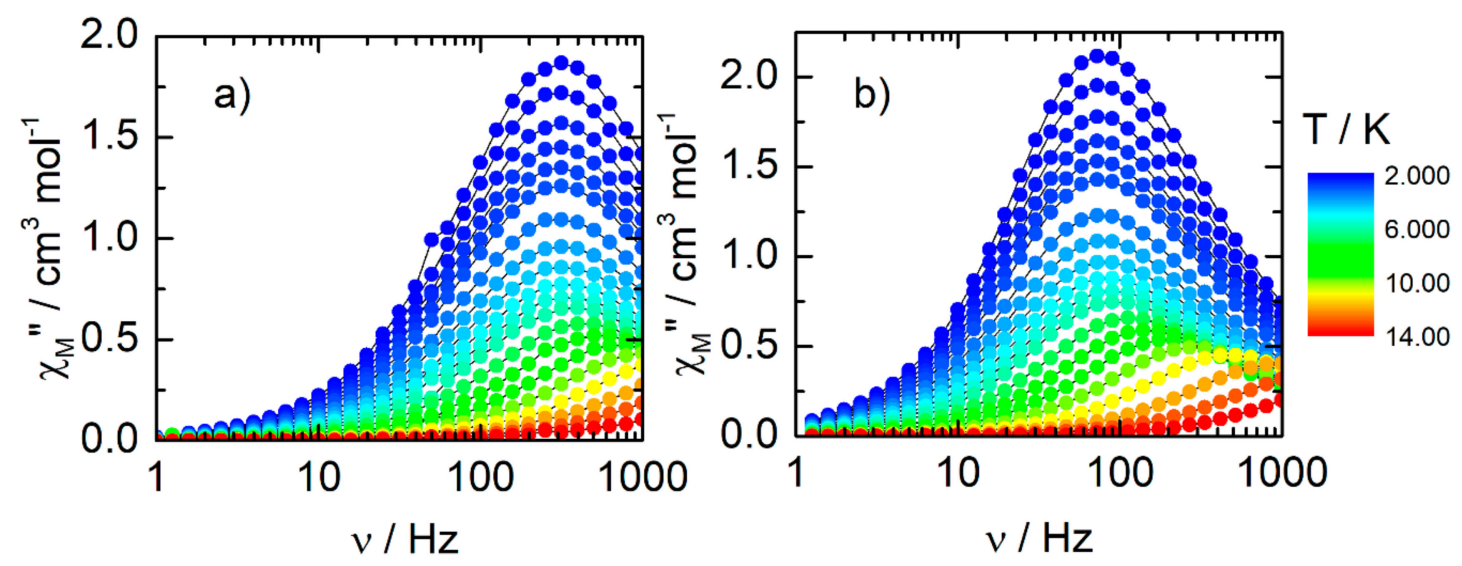

Figure 5. Frequency dependence of $\chi_{\mathrm{M}}$ " between 2 and $14 \mathrm{~K}$ for (a) $\mathbf{1}$ and for (b) $\mathbf{2}$ in the zero applied magnetic field.

The out-of-phase component intensity of the magnetization is in agreement with the fact that almost $100 \%$ of the sample slowly relaxes, as shown by the normalized Argand (Figures S5 and S6). The Arrhenius plots of the relaxation time depicted in Figure 6 could be fitted in the zero field with a combination of two thermally activated regimes (Orbach and Raman) and one thermally independent regime (QTM): $\tau^{-1}=\tau_{0}{ }^{-1} \exp (-\Delta / \mathrm{kT})+\mathrm{CT}^{\mathrm{n}}+\tau_{\mathrm{TI}}{ }^{-1}$ (where $\tau$ is the relaxation time, $\Delta$ is the energy 
barrier, $\mathrm{C}$ is the Raman constant, $\mathrm{n}$ is the exponential constant describing the thermal dependence of the Raman and $\tau_{\mathrm{TI}}$ is the relaxation time for the thermal independent regime). The best fits depicted in Figure 6 were obtained using the parameters of Table 1.

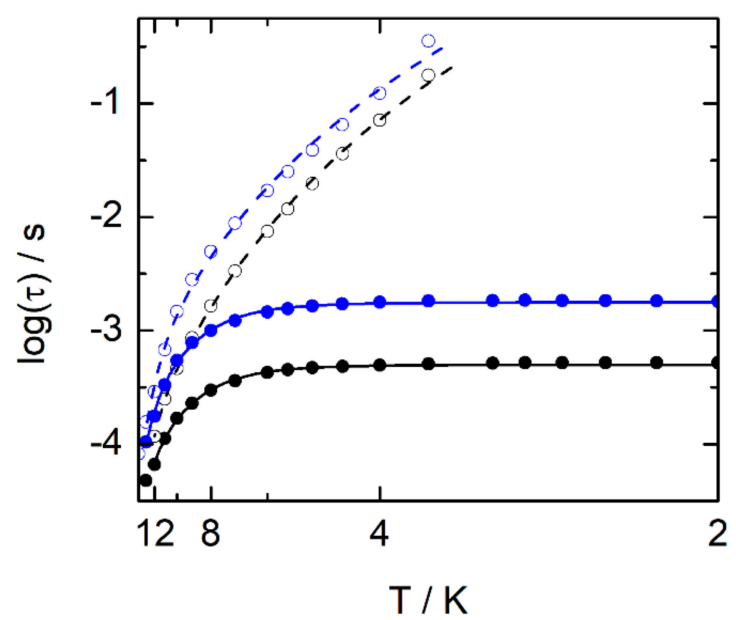

Figure 6. Temperature dependences of the relaxation times $(\tau)$ at 0 Oe (full black circles) and 1200 Oe (open black circles) for $\mathbf{1}$ and at 0 Oe (full blue circles) and 1000 Oe (open blue circles) for $\mathbf{2}$. Full and dashed lines are the best fitted curves with the parameters given in the text.

Table 1. Dynamic parameters of the different relaxation mechanisms for $\mathbf{1}$ and $\mathbf{2}$.

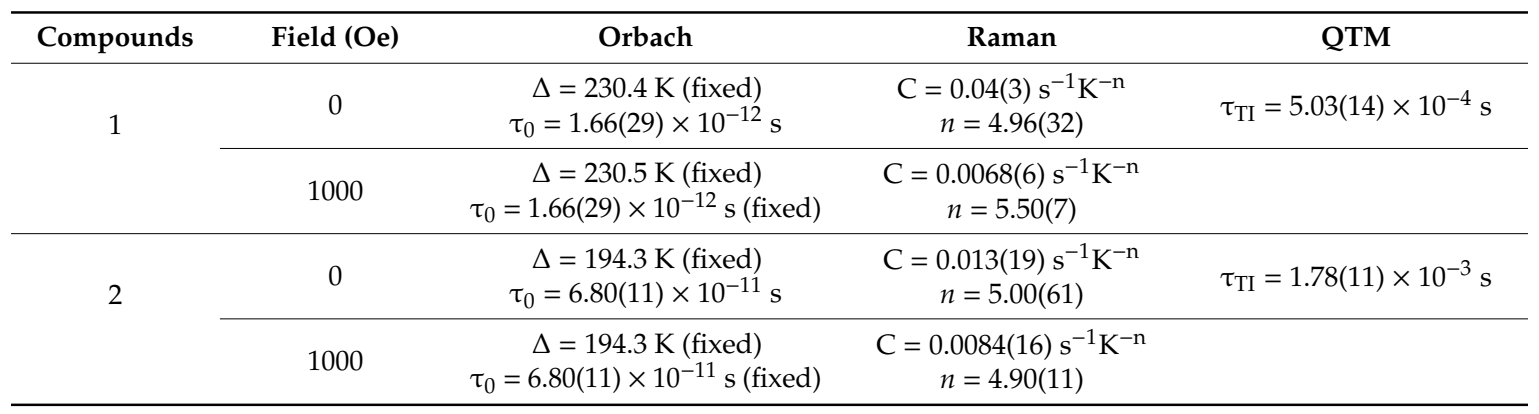

The involvement of the Raman process is supported by the discrepancy between the calculated energy barrier ( $\Delta=230.4 \mathrm{~K}$ for $\mathbf{1}$ and $\Delta=194.3 \mathrm{~K}$ for 2$)$ and the experimental barrier extracted from the high temperature region of the Arrhenius plot $(\Delta=61(5) \mathrm{K}$ for 1 and $\Delta=83(5) \mathrm{K}$ for 2) which can be explained by the operating under-barrier relaxation mechanism [51-54]. It is worth noting that a satisfying fit could only be obtained by fixing the energy gap to the computed value for each compound. The expected $n$ value for Kramers ion should be 9 [48], but the presence of both acoustic and optical phonons could lead to lower values between 2 and 7 [55-57]. The anisotropy barrier values extracted for $\mathbf{1}$ and $\mathbf{2}$ are very close to those found for their analogues involving the 1,10-phenantroline ligand [58,59].

The application of an external magnetic field is efficient in cancelling the QTM. Thus, a field dependence of $\chi_{\mathrm{M}}$ is studied (Figures 7 and S7). For the two compounds, the presence of an external field led to a significant shift of the out-of-phase component to a lower frequency due to the cancelling of the fast relaxation of the magnetization through QTM. 


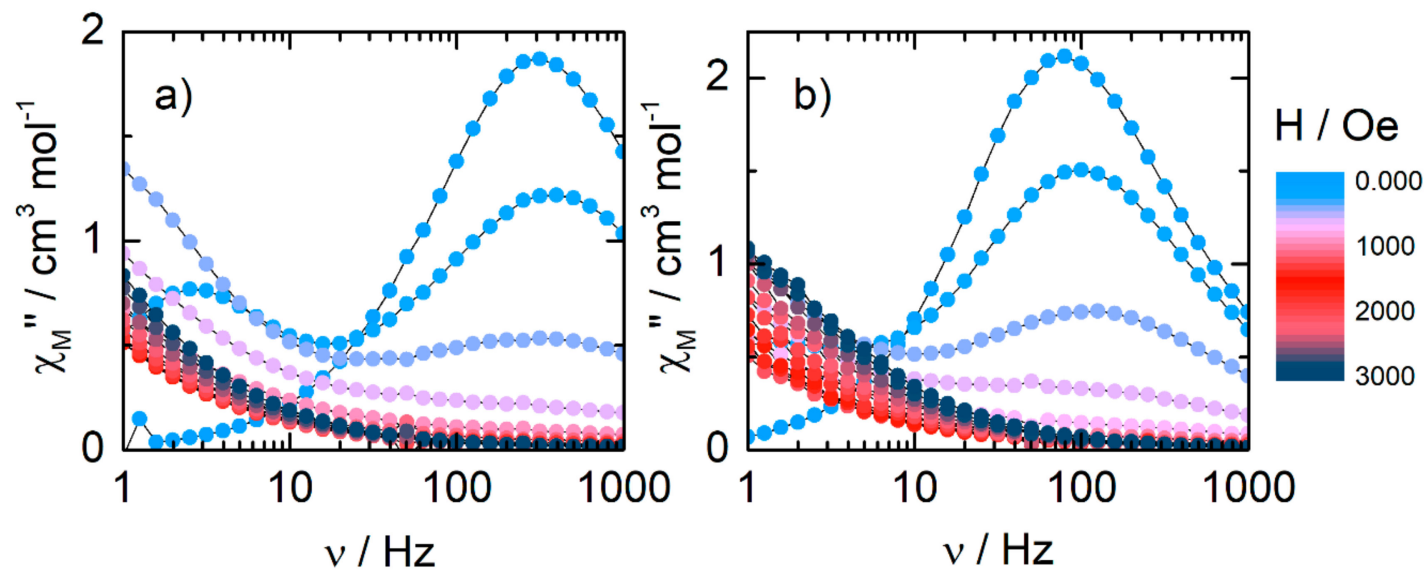

Figure 7. Frequency dependence of $\chi_{\mathrm{M}}{ }^{\prime \prime}$ at $2 \mathrm{~K}$ at various external fields for (a) 1 and (b) 2.

1200 Oe and 1000 Oe have been chosen as optimal values of the applied magnetic field for $\mathbf{1}$ and $\mathbf{2}$, respectively. Under these applied fields, $\mathbf{1}$ and $\mathbf{2}$ highlighted a frequency dependence of the in-phase (Figure S8) and out-of-phase signals of the magnetization (Figure 8). An analysis of the framework of the extended Debye model allowed an extraction of the temperature dependence of the relaxation time (Figure 6, Tables S6 and S7). The out-of-phase component intensity of the magnetization and the normalized Argand indicated that almost the whole sample is slowly relaxing (Figures S9 and S10). The relaxation time follows two thermally dependent relaxation processes (Orbach and Raman) (Table 1). The best fit was obtained by fixing the Orbach process with the energy barrier $(\Delta)$ and relaxation time $\left(\tau_{0}\right)$ determined for the corresponding compound for $\mathrm{H}=0$ Oe, since such a magnetic relaxation should be field-independent.
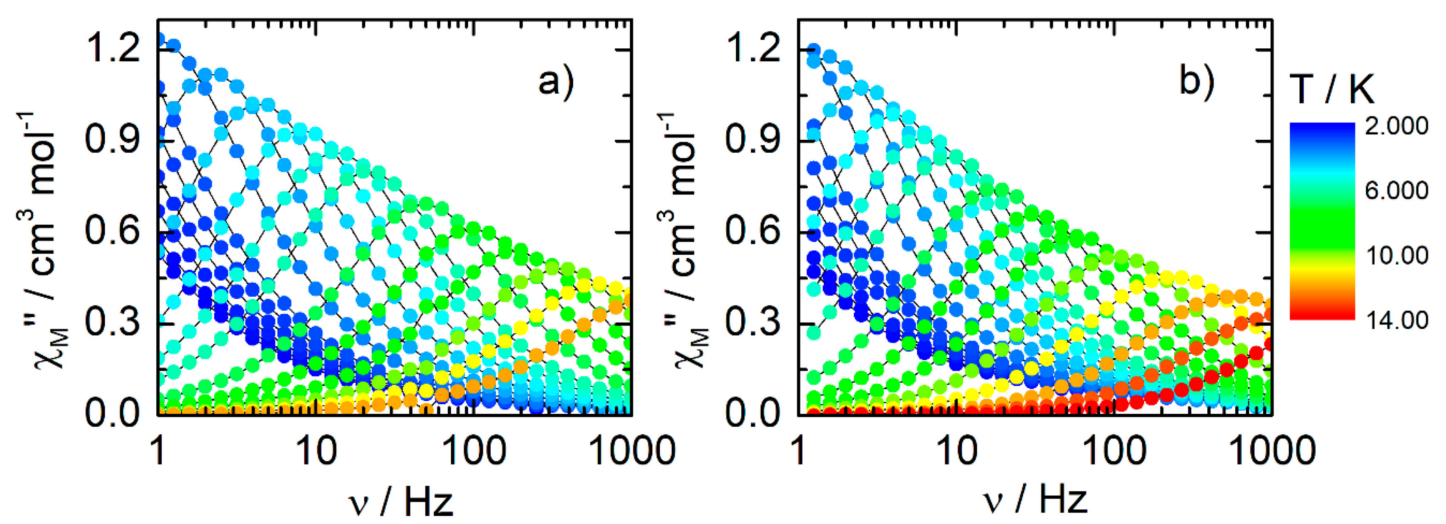

Figure 8. Frequency dependence of $\chi_{\mathrm{M}}{ }^{\prime \prime}(\mathbf{a})$ between 2 and $12 \mathrm{~K}$ for $\mathbf{1}$ and (b) between 2 and $14 \mathrm{~K}$ for 2 in 1200 and 1000 Oe applied magnetic fields, respectively.

Replacing the tta- (compound 1) with hfac- (compound 2) led to a slowing down of the magnetic relaxation time, which is the inverse trend to that usually observed for such chemical engineering [45-47]. Indeed, from a molecular point of view, the replacement of hfac by $\mathrm{tta}^{-}$led to a decrease of the coordination polyhedron distortion and an increase of the computed energy gap between the ground and first excited states (Tables S2 and S3). Thus, the explanation of the inverse trend might be of intermolecular origin with the presence of a significant antiferromagnetic interaction, as suggested by the quick decreasing of the $\chi_{M} T$ product at a very low temperature (Figure 4). Even if the $\sigma-\pi$ interactions are similar in both compounds, the intermolecular distance between the Dy ${ }^{\mathrm{III}}$ ions, as well as the angles between the magnetic anisotropy vectors, change slightly, leading to a variation of the intermolecular magnetic interactions, which could modify the dynamic magnetic properties. Such a hypothesis is supported by the difference of the frequency dependence of $\chi_{\mathrm{M}}{ }^{\prime \prime}$ at $2 \mathrm{~K}$ under a $200 \mathrm{Oe}$ 
applied field (Figure 7), which displayed a clear double contribution at frequencies of $2.5 \mathrm{and} 400 \mathrm{~Hz}$ for 1 but not for 2 . Such an observation should be an indication of stronger intermolecular dipolar interactions in $\mathbf{1}$ than in 2 [60].

\section{Conclusions}

In this article, two mononuclear Dy ${ }^{\mathrm{III}}$ complexes involving the 1,10-phenantroline-5,6-dione ligand (L) were structurally and magnetically studied. X-ray diffraction on a single crystal revealed a supramolecular assembly of four mononuclear compounds through $\sigma-\pi$ interactions for the two $\left[\mathrm{Dy}(\mathrm{tta})_{3}(\mathrm{~L})\right](\mathbf{1})$ and $\left[\mathrm{Dy}(\mathrm{hfac})_{3}(\mathrm{~L})\right](\mathbf{2})$ derivatives. Both compounds behaved as a Single-Molecule Magnet in a zero applied magnetic field with the relaxation of the magnetization occurring through Orbach, Raman and QTM mechanisms. The latter could be efficiently cancelled under an optimal applied field, leading to the slowing of the magnetic relaxation. The experimental magnetic properties could be reproduced and rationalized by ab initio calculations. In zero and applied magnetic fields, 2 displayed better performances than 1, which is in contradiction to what is usually observed when changing the tta- ancillary ligand with hfac' ${ }^{-}$Such observations might be attributed to variations of the intermolecular dipolar interaction.

\section{Materials and Methods}

\subsection{Synthesis General Procedures and Materials}

The dysprosium complexes $\mathrm{Dy}(\mathrm{tta})_{3} \cdot 2 \mathrm{H}_{2} \mathrm{O}\left(\mathrm{tta}^{-}=\right.$2-thenoyltrifluoroacetonate anion) [61] and Dy (hfac) $)_{3} \cdot 2 \mathrm{H}_{2} \mathrm{O}$ [62], as well as the 1,10-phenantroline-5,6-dione ligand [63] (L), were synthesized following previously reported methods. All other reagents were commercially available and used without further purification.

\subsection{Synthesis of Complexes $\left[D y(t t a)_{3}(L)\right](\mathbf{1})$ and $\left[D y(h f a c)_{3}(L)\right](\mathbf{2})$}

$\left[D y(t a)_{3}(\mathbf{L})\right](\mathbf{1}) .10 .0 \mathrm{mg}$ of $\mathbf{L}(0.048 \mathrm{mmol})$ were suspended in $10 \mathrm{~mL}$ of $\mathrm{CH}_{2} \mathrm{Cl}_{2}$, and then a solution of $\mathrm{CH}_{2} \mathrm{Cl}_{2}(9 \mathrm{~mL})$ containing $41.0 \mathrm{mg}$ of Dy(tta $)_{3} \cdot 2 \mathrm{H}_{2} \mathrm{O}(0.048 \mathrm{mmol})$ was added. The bright yellow suspension of $\mathbf{L}$ turned greenish with the addition of the Dy ${ }^{\mathrm{III}}$ salt. After 60 min of stirring at room temperature, $30 \mathrm{~mL}$ of $n$-hexane were layered. Suitable yellow single crystals for $\mathrm{X}$-ray studies were obtained by slow diffusion. Yield (determined from isolated single crystals): $33 \mathrm{mg}$ (67\%). Anal. Calcd (\%) for $\mathrm{C}_{36} \mathrm{H}_{18} \mathrm{DyF}_{9} \mathrm{~N}_{2} \mathrm{O}_{8} \mathrm{~S}_{3}$ : C 41.69, $\mathrm{H}$ 1.74, N 2.70; found: C 41.74, H 1.83, N 2.66.

$\left[D y(h f a c)_{3}(L)\right](2)$. The same experimental protocol was used replacing the Dy(tta $)_{3} \cdot 2 \mathrm{H}_{2} \mathrm{O}$ salt

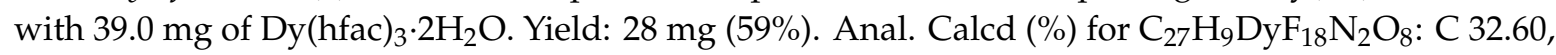
H 0.91, N 2.82; found: C 32.57, H 0.99, N 2.88.

\subsection{Crystallography}

Single crystals of 1 and 2 were mounted on an APEXIII D8 VENTURE Bruker-AXS diffractometer for data collection $\left(\mathrm{MoK}_{\alpha}\right.$ radiation source, $\lambda=0.71073 \AA$ ), from the Centre de Diffractométrie (CDIFX), Université de Rennes 1, France (Table S1). The structure was solved and refined, respectively, with a direct method using the SHELXT program [64] and a full matrix least-squares method on $\mathrm{F}^{2}$ using the SHELXL-14/7 program [65]. The complete crystal structure results as a CIF file are deposited as Supporting Information. The CCDC number is 1,991,212 for $\mathbf{1}$ and 1,991,211 for 2.

\subsection{Physical Measurements}

The elemental analyses of the compounds were performed at the Centre Régional de Mesures Physiques de 1'Ouest, Rennes. A Quantum Design MPMS-XL SQUID magnetometer was used to measure the dc magnetic susceptibility from solid polycrystalline samples. A $0.2 \mathrm{kOe}, 2 \mathrm{kOe}$ and $10 \mathrm{kOe}$ magnetic field was applied respectively for the temperature ranges of 2-20 K, 20-80 K and 80-300 K. 
These measurements were all corrected for the diamagnetic contribution, as calculated with Pascal's constants. The ac magnetic susceptibility measurements were performed on the same apparatus.

\subsection{Computational Details}

The atomic positions were extracted from the X-ray diffraction crystal structures of the $\mathbf{1}$ and 2 compounds. The wavefunction theory calculations (WFT) were carried out with the help of the OpenMolcas software package [66]. In these calculations, the complete active space self-consistent field [67] (CASSCF) approach was used to treat the static correlation effects arising from the partially filled $4 f$ shell of the Dy(III) ion. The second-order Douglas-Kroll-Hess [68-71] scalar relativistic (SR) Hamiltonian was used to treat the scalar relativistic effects, in combination with the all-electron atomic natural orbital relativistically contracted (ANO-RCC) basis set from the Molcas library [72-74]. The basis sets were contracted to the triple- $\zeta$ plus polarization (TZP) quality for the Dy and $\mathrm{O}$ atoms bonded to the lanthanide (Dy $=25 \mathrm{~s} 22 \mathrm{p} 15 \mathrm{~d} 11 \mathrm{f} 4 \mathrm{~g} 2 \mathrm{~h} / 8 \mathrm{~s} 7 \mathrm{p} 4 \mathrm{~d} 3 \mathrm{f} 2 \mathrm{~g} 1 \mathrm{~h} ; \mathrm{O}=14 \mathrm{~s} 9 \mathrm{p} 5 \mathrm{~d} 3 \mathrm{f} 2 \mathrm{~g} / 4 \mathrm{~s} 3 \mathrm{p} 2 \mathrm{~d} 1 \mathrm{f}$ ), and to the double- $\zeta$ quality for $\mathrm{H}, \mathrm{C}, \mathrm{F}$ and $\mathrm{S}$ atoms $(\mathrm{H}=8 \mathrm{~s} 4 \mathrm{p} 3 \mathrm{~d} 1 \mathrm{f} / 2 \mathrm{~s} ; \mathrm{C}=14 \mathrm{~s} 9 \mathrm{p} 5 \mathrm{~d} 3 \mathrm{f} 2 \mathrm{~g} / 3 \mathrm{~s} 2 \mathrm{p}, \mathrm{F}=14 \mathrm{~s} 9 \mathrm{p} 5 \mathrm{~d} 3 \mathrm{f} 2 \mathrm{~g} / 3 \mathrm{~s} 2 \mathrm{p}$, $\mathrm{S}=17 \mathrm{~s} 12 \mathrm{p} 5 \mathrm{~d} 4 \mathrm{f} 2 \mathrm{~g} / 4 \mathrm{~s} 3 \mathrm{p} 1 \mathrm{~d})$. The calculations employed the state-averaged formalism at the $\mathrm{SR}$ level by taking into account the 21 sextet, the 224 quartet and the 490 doublet spin states arising from the 9 electrons spanning the seven $4 \mathrm{f}$ orbitals (i.e., CAS $(9,7)$ ). The spin-orbit coupling (SOC) was then introduced within a state interaction among the basis of calculated SR states using the restricted active space state interaction (RASSI) approach [75]. Herein the SOC matrix is diagonalized using the calculated 21 SR sextet, 224 SR quartet and the 98th lowest SR doublet spin states. The EPR $g$-factors were calculated according to [76], as implemented in the RASSI module of OpenMolcas, whereas the magnetic susceptibility and magnetization calculations were performed using the Single-Aniso of OpenMolcas, as detailed in [77].

The molecular electrostatic potential is calculated from the ab-initio LOPROP charge analysis [78]:

$$
V\left(r_{i}\right)=\sum_{i}^{N} \frac{q_{i}}{\left|r_{i}-r\right|}+\frac{p_{i} \cdot r_{i}}{\left|r_{i}-r\right|^{3}}+\frac{r_{i} \cdot\left(Q_{i} \times r_{i}\right)}{\left|r_{i}-r\right|^{5}}
$$

where $q_{i}, p, Q_{i}$ and $r_{i}$ are respectively the charge, dipole, quadrupole moments and displacement vector of the $\mathrm{i}$-th atom. The resulting molecular electrostatic potential is mapped and represented using the home-made CAMMEL code. The potential is drawn on a sphere defined by the user around the central lanthanide ion, for a given state (ground state in this case). For a clearer representation of the potential, the intensity can be directly related to both the color (red = high potential and blue = low potential) and the height of the irregularities. This program has already been used in previous works to give some hints on the orientation of magnetization axes [79,80].

Supplementary Materials: The following are available online at http://www.mdpi.com/2312-7481/6/2/19/s1, Figure S1. ORTEP view of 1. Thermal ellipsoids are drawn at 30\% probability; Figure S2. ORTEP view of 2. Thermal ellipsoids are drawn at 30\% probability; Figure S3. Molecular Electrostatic potential centered on the lanthanide ion for $\mathbf{1}$ (left) and $\mathbf{2}$ (right). The orientation of the ground state anisotropy axis is represented as a dark line. Figure S4. Frequency dependence of in-phase $\left(\chi_{M}{ }^{\prime}\right)$ and out-of-phase components $\left(\chi_{M}{ }^{\prime \prime}\right)$ at $5 \mathrm{~K}$ for 1 in a zero applied magnetic field. Red lines are the best fitted curves; Figure S5. Frequency dependence of $\chi_{M}{ }^{\prime}$ in the temperature range (a) 2-14 K for 1 and (b) 2-20 K for 2 in a zero applied magnetic field; Figure S6. Normalized Argand plot between 2 and $14 \mathrm{~K}$ for 1 in a zero applied magnetic field; Figure S7. Normalized Argand plot between 2 and $14 \mathrm{~K}$ for 2 in a zero applied magnetic field; Figure S8. Frequency dependence of $\chi_{M}^{\prime}$ at $2 \mathrm{~K}^{\prime}$ at various external fields for (a) 1 and (b) 2; Figure S9. Frequency dependence of $\chi_{\mathrm{M}}{ }^{\prime}$ in the temperature range 2-14 K for (a) 1 and for (b) 2 in a 1200 and 1000 Oe applied magnetic field, respectively; Figure S10. Normalized Argand plot between 2 and $14 \mathrm{~K}$ for 1 in a 1200 Oe applied magnetic field; Figure S11. Normalized Argand plot between 2 and $14 \mathrm{~K}$ for 2 in a 1000 Oe applied magnetic field; Table S1: X-ray crystallographic data for 1 and 2; Table S2: Computed energies, $g$-tensor and wavefunction composition of the ground state doublet in the effective spin $1 / 2$ model for 1; Table S3: Computed energies, $g$-tensor and wavefunction composition of the ground state doublet in the effective spin 1/2 model for 2; Table S4: Best fitted parameters $\left(\chi_{T}, \chi_{S}, \tau\right.$ and $\left.\alpha\right)$ with the extended Debye model 1 at 0 Oe in the temperature range $2-13 \mathrm{~K}$; Table S5: Best fitted parameters $\left(\chi_{T}, \chi_{S}, \tau\right.$ and $\left.\alpha\right)$ with the extended Debye model 2 at 0 Oe in the temperature range $2-13$ K; Table S6: Best fitted parameters $\left(\chi_{T}, \chi_{S}, \tau\right.$ and $\left.\alpha\right)$ with the 
extended Debye model 1 at 1200 Oe in the temperature range 3.5-12 K; Table S7: Best fitted parameters $\left(\chi_{\mathrm{T}}, \chi_{\mathrm{S}}, \tau\right.$ and $\alpha$ ) with the extended Debye model 2 at 1000 Oe in the temperature range 3.5-14 K.

Author Contributions: O.G. performed the whole syntheses; V.D. realized the structure refinements; O.C. and J.F.G. performed and analyzed the magnetic data, V.M. and B.l.G. performed the ab initio calculations. F.P. conceived and designed the experiments and write the article with contributions of O.C and B.l.G. All authors have read and agreed to the published version of the manuscript.

Funding: This work was supported by CNRS, Universite de Rennes 1 and the European Commission through the ERC-CoG 725184 MULTIPROSMM (project n. 725184).

Acknowledgments: B.L.G. and V.M. thank the French GENCI/IDRIS-CINES center for high-performance computing resources.

Conflicts of Interest: The authors declare no conflict of interest. The founding sponsors had no role in the design of the study; in the collection, analyses, or interpretation of data; in the writing of the manuscript, and in the decision to publish the results.

\section{Abbreviations}

The following abbreviations are used in this manuscript:

$\begin{array}{ll}\text { SMM } & \begin{array}{l}\text { Single Molecule Magnet } \\ \text { QTM }\end{array} \\ \mathrm{CH}_{2} \mathrm{Cl}_{2} & \begin{array}{l}\text { Quantum Tunneling of the Magnetization } \\ \text { dichloromethane }\end{array} \\ \mathrm{tta}^{-} & \text {2-thenoyltrifluoroacetonate } \\ \mathrm{hfac}^{-} & \text {1,1,1,5,5,5-hexafluoroacetylacetonate } \\ \text { CASSCF } & \text { Complete Active Space Self-Consistent Field } \\ \text { RASSI-SO } & \text { Restricted Active Space State Interaction - Spin-Orbit }\end{array}$

\section{References}

1. Bünzli, J.C.G.; Chauvin, A.-S.; Kim, H.K.; Deiters, E.; Eliseeva, S.V. Lanthanide luminescence efficiency in eight- and nine-coordinate complexes: Role of the radiative lifetime. Coord. Chem. Rev. 2010, 254, 2623-2633. [CrossRef]

2. Bünzli, J.C.G. On the design of highly luminescent lanthanide complexes. Coord. Chem. Rev. 2015, 293-294, 19-47. [CrossRef]

3. Woodruff, D.N.; Winpenny, R.E.P.; Layfield, R.A. Lanthanide Single-Molecule Magnets. Chem. Rev. 2013, 113, 5110-5148. [CrossRef]

4. Sessoli, R.; Powell, A.K. Strategies towards single molecule magnets based on lanthanide ions. Coord. Chem. Rev. 2009, 253, 2328-2341. [CrossRef]

5. Pointillart, F.; Cador, O.; Le Guennic, B.; Ouahab, L. Uncommon Lanthanide ions in purely 4 f Single Molecule Magnets. Coord. Chem. Rev. 2017, 346, 150-175. [CrossRef]

6. Bünzli, J.-C.G. Lanthanide Luminescence for Biomedical Analyses and Imaging. Chem. Rev. 2010, 110, 2729-2755. [CrossRef]

7. Duke, R.M.; Veale, E.B.; Pfeffer, F.M.; Kruger, P.E.; Gunnlaugsson, T. Colorimetric and fluorescent anion sensors: An overview of recent developments in the use of 1,8-naphthalimide-based chemsensors. Chem. Soc. Rev. 2010, 39, 3936-3953. [CrossRef]

8. Kuriki, K.; Koike, Y.; Okamoto, Y. Plastic Optical Fiber Lasers and Amplifiers Containing Lanthanide Complexes. Chem. Rev. 2002, 102, 2347-2356. [CrossRef]

9. Moore, E.G.; Samuel, A.P.S.; Raymond, K.N. From Antenna to Assay: Lessons Learned in Lanthanide Luminescence. Acc. Chem. Res. 2009, 42, 542-552, and references therein. [CrossRef]

10. Beeby, A.; Botchway, S.W.; Clarkson, I.M.; Faulkner, S.; Parker, A.M.; Parker, D.; Williams, J.A.G. Luminescence imaging microscopy and lifetime mapping using kinetically stable lanthanide(III) complexes. J. Photochem. Photobiol. B 2000, 57, 83-89. [CrossRef]

11. Grichine, A.; Haefele, A.; Pascal, S.; Duperray, A.; Michel, R.; Andraud, C.; Maury, O. Millisecond lifetime imaging with a europium complex using a commercial confocal microscope under one or two-photon excitation. Chem. Sci. 2014, 5, 3475-3485. [CrossRef]

12. Van Vleck, J.H. The Puzzle of Rare-earth Spectra in Solids. J. Phys. Chem. 1937, 41, 67-80. [CrossRef] 
13. D'Aléo, A.; Pointillart, F.; Ouahab, L.; Andraud, C.; Maury, O. Charge transfer excited states sensitization of lanthanide emitting from the visible to the near-infrared. Coord. Chem. Rev. 2012, 256, 1604-1620. [CrossRef]

14. Pointillart, F.; Le Guennic, B.; Cador, O.; Maury, O.; Ouahab, L. Lanthanide Ion and Tetrathiafulvalene-Based Ligand as a "Magic" Couple toward Luminescence, Single Molecule Magnets, and Magnetostructural Correlations. Acc. Chem. Res. 2015, 48, 2834-2842. [CrossRef]

15. Zhu, Z.; Guo, M.; Li, X.-L.; Tang, J. Molecular magnetism of lanthanide: Advances and perspectives. Coord. Chem. Rev. 2019, 378, 350-364. [CrossRef]

16. Mannini, M.; Pineider, F.; Sainctavit, P.; Danieli, C.; Otero, E.; Sciancalepore, C.; Talarico, A.M.; Arrio, M.-A.; Cornia, A.; Gatteschi, D.; et al. Magnetic memory of a single-molecule quantum magnet wired to a gold surface. Nat. Mater. 2009, 8, 194-197. [CrossRef]

17. Thiele, S.; Balestro, F.; Ballou, R.; Klyatskaya, S.; Ruben, M.; Wernsdorfer, W. Electrically driven nuclear spin resonance in single-molecule magnets. Science 2014, 344, 1135-1138. [CrossRef]

18. Pedersen, K.S.; Ariciu, A.-M.; McAdams, S.; Weihe, H.; Bendix, J.; Tuna, F.; Piligkos, S. Toward Molecular $4 f$ Single-Ion Magnet Qubits. J. Am. Chem. Soc. 2016, 138, 5801-5804. [CrossRef]

19. Rinehart, J.D.; Long, J.R. Exploiting single-ion anisotropy in the design of f-element single-molecule magnets. Chem. Sci. 2011, 2, 2078-2085. [CrossRef]

20. Guo, F.-S.; Day, B.-M.; Chen, Y.-C.; Tong, M.-L.; Mansikkamäki, A.; Layfield, R.A. A Dysprosium Metallocene Single-Molecule Magnet Functioning at the Axial Limit. Angew. Chem. Int. Ed. 2017, 56, 11445-11449. [CrossRef]

21. Goodwin, C.A.P.; Ortu, F.; Reta, D.; Chilton, N.F.; Mills, D.P. Molecular magnetic hysteresis at 60 kelvin in dysprosocenium. Nature 2017, 548, 439-442. [CrossRef] [PubMed]

22. McClain, K.R.; Gould, C.A.; Chakarawet, K.; Teat, S.J.; Groshens, T.J.; Long, J.R.; Harvey, B.G. High-temperature magnetic blocking and magneto-structural correlations in a series of dysprosium(III) metallocenium single-molecule magnets. Chem. Sci. 2018, 9, 8492-8503. [CrossRef] [PubMed]

23. Guo, F.-S.; Day, B.-M.; Chen, Y.-C.; Tong, M.-L.; Mansikkamäki, A.; Layfield, R.A. Magnetic hysteresis up to 80 kelvin in a dysprosium metallocene single-molecule magnet. Science 2018, 362, 1400-1403. [CrossRef] [PubMed]

24. Feng, M.; Pointillart, F.; Lefeuvre, B.; Dorcet, V.; Golhen, S.; Cador, O.; Ouahab, L. Multiple Single-Molecule Magnet Behaviors in Dysprosium Dinuclear Complexes Involving a Multiple Functionalized Tetrathiafulvalene-Based Ligand. Inorg. Chem. 2015, 54, 4021-4028. [CrossRef] [PubMed]

25. Pointillart, F.; Guizouarn, T.; Lefeuvre, B.; Golhen, S.; Cador, O.; Ouahab, L. Rational Design of a Lanthanide-Based Complex Featuring Different Single-Molecule Magnets. Chem. Eur. J. 2015, 21, 16929-16934. [CrossRef] [PubMed]

26. Speed, S.; Feng, M.; Fernandez Garcia, G.; Pointillart, F.; Lefeuvre, B.; Riobé, F.; Golhen, S.; Le Guennic, B.; Totti, F.; Guyot, Y.; et al. Lanthanide complexes involving multichelating TTF-based ligands. Inorg. Chem. Front. 2017, 4, 604-617. [CrossRef]

27. Cador, O.; Le Guennic, B.; Ouahab, L.; Pointillart, F. Decorated Tetrathiafulvalene-Based Ligands: Powerful Chemical Tools for the Design of Single-Molecule Magnets. Eur. J. Inorg. Chem. 2020, 148-164. [CrossRef]

28. Shukla, A.D.; Das, A. Redox responsive binuclear complexes using 5,6-dihydroxy-1,10-phenantroline as a bridging ligands: Synthesis, characterization and physicochemical studies. Polyhedron 2000, 19, 2605-2611. [CrossRef]

29. Yuasa, J.; Suenobu, T.; Fukuzumi, S. Thermochromism of Metal Ion Complexes of Semiquinone Radical Anions. Control of Equilibria between Diamagnetic and Paramagnetic Species by Lewis Acids. J. Phys. Chem. A 2005, 109, 9356-9362. [CrossRef]

30. Minkin, V.I.; Starikova, A.A.; Starikov, A.G. Quantum chemical modeling of magnetically bistable metal coordination compounds. Synchronization of spin crossover, valence tautomerism and charge transfer induced spin transition mechanisms. Dalton Trans. 2016, 45, 12103-12113. [CrossRef]

31. Cador, O.; Le Guennic, B.; Pointillart, F. Electro-Activity and Magnetic Switching in Lanthanide-Based Single-Molecule Magnets. Inorg. Chem. Front. 2019, 6, 3398-3417. [CrossRef]

32. Tropiano, M.; Kilah, N.L.; Morten, M.; Rahman, H.; Davis, J.J.; Beer, P.D.; Faulkner, S. Reversible Luminescence Switching of a Redox-Active Ferrocene-Europium Dyad. J. Am. Chem. Soc. 2011, 133, 11847-11849. [CrossRef] [PubMed] 
33. Molloy, J.K.; Jarjayes, O.; Philouze, C.; Fedele, L.; Imbert, D.; Thomas, F. A redox active switch for lanthanide luminescence in phenolate complexes. Chem. Commun. 2017, 53, 605-608. [CrossRef] [PubMed]

34. Subhan, M.A.; Rahman, M.S.; Alam, K.; Hasan, M.M. Spectroscopic analysis, DNA binding and antimicrobial activities of metal complexes with phendione and its derivative. Spectrochim. Acta A 2014, 118, 944-950. [CrossRef] [PubMed]

35. Li, Y.; Zhang, D.; Xu, H.; Tao, X.; Shen, Y. Preparation and Photoluminescent Properties of Doped Ternary Europium Complexes Bearing 1-(Naphthalen-2-yl)-3-phenylpropane-1,3-dione. Adv. Mater. Res. 2011, 239-242, 3161-3164. [CrossRef]

36. Zhang, X.-F.; Xu, C.-J.; Wan, J. Mono- and dinuclear europium(III) complexes with thenoyltrifluoroacetone and 1,10-phenantroline-5,6-dione. Chem. Mon. 2014, 145, 1913-1917. [CrossRef]

37. Song, Y.-M.; Xu, J.-P.; Ding, L.; Hou, Q.; Liu, J.-W.; Zhu, Z.-L. Syntheses, characterization and biological activities of rare earth metal complexes with curcumin and 1,10-phenantroline-5,6-dione. J. Inorg. Biochem. 2009, 103, 396-400. [CrossRef]

38. Li, Y.; Li, Y.; Xu, H.; Tao, X.; Zhang, D.; Shen, Y. Synthesis and photoluminescent properties of doped ternary Eu1-xLnx(NPPD) 3 .DPQ complexes. J. Rare Earths 2010, 28, 654-659. [CrossRef]

39. Li, Y.; Li, Y.; Chu, Y.; Tao, X.; Xu, H.; Shen, Y.; Zheng, A. An experimental and quantum mechanical study on luminescence properties of $\mathrm{SM}(\beta-\mathrm{Nbm})_{3} \cdot \mathrm{Pd}$. J. Lumin. 2012, 132, 1663-1667. [CrossRef]

40. Shavaleev, N.M.; Moorcraft, L.P.; Pope, S.J.A.; Bell, Z.R.; Faulkner, S.; Ward, M.D. Sensitized near-infrared emission from lanthanides using a covalently-attached $\mathrm{Pt}(\mathrm{II})$ fragment as an antenna group. Chem. Commun. 2003, 1134-1135. [CrossRef]

41. Shavaleev, N.M.; Moorcraft, L.P.; Pope, S.J.A.; Bell, Z.R.; Faulkner, S.; Ward, M.D. Sensitized Near-Infrared Emission from Complexes of $\mathrm{Yb}^{\mathrm{III}}, \mathrm{Nd}^{\mathrm{III}}$ and $\mathrm{Er}^{\mathrm{III}}$ by Energy-Transfer from Covalently Attached $\mathrm{Pt}^{\mathrm{II}}$-Based Antenna Units. Chem. Eur. J. 2013, 9, 5283-5291. [CrossRef] [PubMed]

42. Hickson, J.R.; Horsewill, S.J.; Bamforth, C.; McGuire, J.; Wilson, C.; Sproules, S.; Farnaby, J.H. The modular synthesis of rare earth-transition metal heterobimetallic complexes utilizing a redox-active ligand. Dalton Trans. 2018, 47, 10692-10701. [CrossRef] [PubMed]

43. Llunell, M.; Casanova, D.; Cirera, J.; Alemany, P.; Alvarez, S. SHAPE Program for the Stereochemical Analysis of Molecular Fragments by Means of Continuous Shape Measures and Associated Tools; Departament de Quimica Fisica, Departament de Quimica Inorganica and Institut de Quimica Teorica i Computacional—Universitat de Barcelona: Barcelona, Spain, 2010.

44. Chen, G.-J.; Guo, Y.-N.; Tian, J.-L.; Tang, J.; Gu, W.; Liu, X.; Yan, S.-P.; Cheng, P.; Liao, D.-Z. Enhancing Anisotropy Barriers of Dysprosium(III) Single-Ion Magnets. Chem. Eur. J. 2012, 18, 2484-2487. [CrossRef]

45. Pointillart, F.; Jung, J.; Berraud-Pache, R.; Le Guennic, B.; Dorcet, V.; Golhen, S.; Cador, O.; Maury, O.; Guyot, Y.; Decurtins, S.; et al. Luminescence and Single-Molecule Magnet Behavior in Lanthanide Complexes Involving a Tetrathiafulvalene-Fused Dipyridophenazine Ligand. Inorg. Chem. 2015, 54, 5384-5397. [CrossRef]

46. Da Cunha, T.T.; Jung, J.; Boulon, M.-E.; Campo, G.; Pointillart, F.; Pereira, C.L.M.; Le Guennic, B.; Cador, O.; Bernot, K.; Pineider, F.; et al. Magnetic Poles Determinations and Robustness of Memory Effect upon Solubilization in a Dy III-Based Single Ion Magnet. J. Am. Chem. Soc. 2013, 135, 16332-16335. [CrossRef]

47. Fernandez-Garcia, G.; Flores Gonzalez, J.; Ou-Yang, J.-K.; Saleh, N.; Pointillart, F.; Cador, O.; Guizouarn, T.; Totti, F.; Ouahab, L.; Crassous, J.; et al. Slow Magnetic Relaxation in Chiral Helicene-Based Coordination Complex of Dysprosium. Magnetochemistry 2017, 3, 2. [CrossRef]

48. Kahn, O. Molecular Magnetism; VCH: Weinhem, Germany, 1993.

49. Dekker, C.; Arts, A.F.M.; Wijn, H.W.; van Duyneveldt, A.J.; Mydosh, J.A. Activated dynamics in a two-dimensional Ising spin glass: Rb2Cu1-xCoxF4. Phys. Rev. B 1989, 40, 11243-11251. [CrossRef] [PubMed]

50. Cole, K.S.; Cole, R.H. Dipersion and Absorption in Dielectrics I. Alternating Current Characteristics. J. Chem. Phys. 1941, 9, 341-351. [CrossRef]

51. Zadrozny, J.M.; Atanasov, M.; Bryan, A.M.; Lin, C.-Y.; Rekken, B.D.; Power, P.P.; Neese, F.; Long, J.R. Slow magnetization dynamics in a series of two-coordinate iron(II) complexes. Chem. Sci. 2013, 4, 125-138. [CrossRef]

52. Pedersen, K.S.; Dreiser, J.; Weihe, H.; Sibille, R.; Johannesen, H.V.; Sorensen, M.A.; Nielsen, B.E.; Sigrist, M.; Mutka, H.; Rols, S.; et al. Design of Single-Molecule Magnets: Insufficiency of the Anisotropy Barrier as the Sole Criterion. Inorg. Chem. 2015, 54, 7600-7606. [CrossRef] 
53. Chibotaru, L.F.; Ungur, L.; Soncini, A. The Origin of Nonmagnetic Kramers Doublets in the Ground State of Dysprosium Triangles: Evidence for a Toroidal Magnetic Moment. Angew. Chem. Int. Ed. 2008, 47, 4126-4129. [CrossRef]

54. Lunghi, A.; Totti, F. The role of Anisotropic Exchange in Single Molecule Magnets: A CASSCF/NEVPT2 Study of the Fe4 SMM Building Block [Fe2(OCH3)2(dbm)4] Dimer. Inorganics 2016, 4, 28. [CrossRef]

55. Singh, A.; Shrivastava, K.N. Optical-acoustic two-phonon relaxation in spin systems. Phys. Status Solidi B 1979, 95, 273-277. [CrossRef]

56. Shirivastava, K.N. Theory of Spin-Lattice Relaxation. Phys. Status Solidi B 1983, 177, 437-458. [CrossRef]

57. Goodwin, C.A.P.; Reta, D.; Ortu, F.; Chilton, N.F.; Mills, D.P. Synthesis and Electronic Structures of Heavy Lanthanide Metallocenium Cations. J. Am. Chem. Soc. 2017, 139, 18714-18724. [CrossRef] [PubMed]

58. Chen, G.-J.; Gao, C.-Y.; Tian, J.-L.; Tang, J.; Gu, W.; Liu, X.; Yan, S.-P.; Liao, D.-Z.; Cheng, P. Coordination-perturbed single-molecule magnet behavior of mononuclear dysprosium complexes. Dalton Trans. 2011, 40, 5579-5583. [CrossRef] [PubMed]

59. Bi, Y.; Guo, Y.-N.; Zhao, L.; Guo, Y.; Lin, S.-Y.; Jiang, S.-D.; Tang, J.; Wang, B.-W.; Gao, S. Capping Ligand Perturbed Slow Magnetic Relaxation in Dysprosium Single-Ion Magnets. Chem. Eur. J. 2011, 17, 12476-12481. [CrossRef] [PubMed]

60. Ho, L.T.A.; Chibotaru, L.F. Intermolecular mechanism for multiple maxima in molecular dynamic susceptibility. Phys. Rev. B 2018, 98, 174418. [CrossRef]

61. Vooshin, A.I.; Shavaleev, N.M.; Kazakov, V.P. Chemiluminescence of praseodymium (III), neodymium (III) and ytterbium (III) $\beta$-diketonates in solution excited from 1,2-dioxetane decomposition and singlet-singlet energy transfer from ketone to rare-earth $\beta$-diketonates. J. Lumin. 2000, 91, 49-58. [CrossRef]

62. Richardson, M.F.; Wagner, W.F.; Sands, D.E. Rare-earth trishexafluoroacetylacetonates and related compounds. J. Inorg. Nucl. Chem. 1968, 30, 1275-1289. [CrossRef]

63. Wang, C.; Lystrom, L.; Yin, H.; Hetu, M.; Kilina, S.; McFarland, S.A.; Sun, W. Increasing the triplet lifetime and extending the ground-state absorption of bicyclometalated $\operatorname{Ir}(\mathrm{III})$ complexes for reverse saturable absorption and photodynamic therapy applications. Dalton Trans. 2016, 45, 16366-16378. [CrossRef] [PubMed]

64. Sheldrick, G.L. SHELXT-Integrated space-group and crystal-structure determination. Acta Crystallogr. Sect. A Found Adv. 2015, 71, 3-8. [CrossRef] [PubMed]

65. Sheldrick, G.M. Crystal structure refinement with SHELXL. Acta Crystallogr. Sect. C Struct. Chem. 2015, 71, 3-8. [CrossRef] [PubMed]

66. Aquilante, F.; Autschbach, J.; Carlson, R.K.; Chibotaru, L.F.; Delcey, M.G.; De Vico, L.; Galván, I.F.; Ferré, N.; Frutos, L.M.; Gagliardi, L.; et al. Molcas 8: New Capabilities for Multiconfigurational Quantum Chemical Calculations Across the Periodic Table. J. Comput. Chem. 2016, 37, 506-541. [CrossRef]

67. Roos, B.O.; Taylor, P.R.; Siegbahn, P.E.M. A Complete Active Space SCF Method (CASSCF) Using a Density Matrix Formulated Super-CI Approach. Chem. Phys. 1980, 48, 157-173. [CrossRef]

68. Douglas, M.; Kroll, N.M. Quantum electrodynamical corrections to the fine structure of helium. Ann. Phys. 1974, 82, 89-155. [CrossRef]

69. Hess, B.A. Applicability of the no-pair equation with free-particle projection operators to atomic and molecular structure calculations. Phys. Rev. A 1985, 32, 756-763. [CrossRef]

70. Hess, B.A. Relativistic electronic-structure calculations employing a two-component no-pair formalism with external-field projection operators. Phys. Rev. A 1986, 33, 3742-3748. [CrossRef]

71. Wolf, A.; Reiher, M.; Hess, B.A. The generalized Douglas-Kroll transformation. J. Chem. Phys. 2002, 117, 9215-9226. [CrossRef]

72. Widmark, P.-O.; Malmqvist, P.-A.; Roos, B.-O. Density matrix averaged atomic natural orbital (ANO) basis sets for correlated molecular wave functions. Theor. Chim. Acta 1990, 77, 291-306. [CrossRef]

73. Roos, B.O.; Lindh, R.; Malmqvist, P.A.; Veryazov, V.; Widmark, P.O. Main Group Atoms and Dimers Studied with A New Relativistic ANO Basis Set. J. Phys. Chem. A. 2004, 108, 2851-2858. [CrossRef]

74. Roos, B.O.; Lindh, R.; Malmqvist, P.-A.; Veryazov, V.; Widmark, P.-O. New Relativistic ANO Basis Sets for Transition Metal Atoms. J. Phys. Chem. A 2005, 109, 6575-6579. [CrossRef] [PubMed]

75. Malmqvist, P.-A.; Roos, B.O.; Schimmelpfennig, B. The Restricted Active Space (RAS) state Interaction Approach with Spin-Orbit Coupling. Chem. Phys. Lett. 2002, 357, 230-240. [CrossRef]

76. Bolvin, H. An alternative approach to the g-matrix: Theory and applications. ChemPhysChem 2006, 7, 1575-1589. [CrossRef] 
77. Chibotaru, L.F.; Ungur, L. Ab Initio Calculation of Anisotropic Magnetic Properties of Complexes. I. Unique Definition of Pseudospin Hamiltonians and Their Derivation. J. Chem. Phys. 2012, 137, 064112. [CrossRef]

78. Gagliardi, L.; Lindh, R.; Karlström, G. Local properties of quantum chemical systems: The LoProp approach. J. Chem. Phys. 2004, 121, 4494-4500. [CrossRef]

79. Zhang, K.; Montigaud, V.; Cador, O.; Li, G.-P.; Le Guennic, B.; Tang, J.; Wang, Y.-Y. Tuning Magnetic Interactions in Dy(III)4 Single-Molecule Magnets. Inorg. Chem. 2018, 57, 8550-8557. [CrossRef]

80. Huang, G.; Fernandez-Garcia, G.; Badiane, I.; Camarra, M.; Freslon, S.; Guillou, O.; Daiguebonne, C.; Totti, F.; Cador, O.; Guizouarn, T.; et al. Magnetic Slow Relaxation in a Metal-Organic Framework Made of Chains of Ferromagnetically Coupled SingleMolecule Magnets. Chem. Eur. J. 2018, 24, 6983-6991. [CrossRef]

(C) 2020 by the authors. Licensee MDPI, Basel, Switzerland. This article is an open access article distributed under the terms and conditions of the Creative Commons Attribution (CC BY) license (http://creativecommons.org/licenses/by/4.0/). 